\title{
FAST AND ROBUST PROTOCOL FOR PRENATAL DIAGNOSIS OF MUCOPOLYSACCHARIDOSIS TYPE II
}

\author{
Ana Carolina Brusius-Facchin ${ }^{1,2}$, Rejane Gus ${ }^{1}$, Maira Burin ${ }^{1}$, Maria \\ Teresa Sanseverino ${ }^{1,2}$, José Antônio Magalhães ${ }^{3}$, Roberto Giugliani ${ }^{1,2,4}$, \\ Sandra Leistner-Segal ${ }^{1,4}$
}

\section{ABSTRACT}

Introduction: Mucopolysaccharidosis type II (MPSII) is an X-linked lysosomal disorder caused by deficiency of iduronate-2-sulfatase (IDS). In this study, we proposed a new protocol for prenatal diagnosis, using DNA obtained from amniotic fluid cells that did not attach to the bottom of the culture flask after the first medium change.

Methods: Four pregnant MPS II carriers were referred to the Medical Genetics Service of Hospital de Clinicas de Porto Alegre for a prenatal diagnosis and identification of the disease, which were performed by polymerase chain reaction (PCR) amplification, restriction fragment length polymorphism, and sequencing according to the mutation previously found in the family.

Results: The analysis indicated the absence of mutation in three fetal materials and the presence of mutation in one case. Concomitantly, cytogenetic and biochemical analyses were performed after 12 days of cell culture, and only one case showed absence of enzyme activity, confirming the molecular analysis.

Conclusions: This diagnostic protocol designed to provide more robust results and safer genetic counseling suggests that DNA obtained from floating amniotic fluid cells can be used as a source of fetal material to allow a faster alternative for prenatal care through molecular analysis. Determination of IDS gene mutation in fetal amniotic fluid cells together with IDS enzyme activity testing is a rapid, sensitive and accurate method for prenatal diagnosis of MPS II for high-risk pregnant women.

Keywords: Prenatal diagnosis; molecular analysis; genetic counselling

Mucopolysaccharidosis type II (MPS II) or Hunter disease, the most frequently diagnosed MPS in Brazill, is a lysosomal disorder caused by deficiency of iduronate-2-sulfatase (IDS), which is involved in the catabolism of glycosaminoglycans dermatan and heparn sulfate ${ }^{2}$. Estimates of the incidence for this disease range from 1:68,000 to 1:320,000 live births.

Considering that MPS II is an X-linked disease, the risk to siblings depends on the carrier status of the mother. For example, if she has the disease-causing mutation in one of her $\mathrm{X}$ chromosomes, the chance of transmitting it in each pregnancy is $50 \%$, and males who inherit the mutation will be affected ${ }^{2}$. Females carrying a mutation in one IDS allele are usually asymptomatic1.

Enzyme activity cannot be used to identify female carriers because, although IDS activity in female carriers is on average about $50 \%$ of that seen in non-affected individuals, considerable overlap is observed ${ }^{3}$.

Prenatal diagnosis has become a major aid to genetic counseling and have been improved by advances in several important areas, such as cytogenetics, biochemistry, and molecular biology. The identification of the IDS mutation in an index case is needed to confirm carrier status and is very important for prenatal diagnosis and genetic counseling in MPSII.

Clin Biomed Res. 2014;34(4):371-373

1 Serviço de Genética Médica, Hospital de Clinicas de Porto Alegre. Porto Alegre, RS, Brazil.

2 Programa de Pós-Graduação em Genética e Biologia Molecular (PPGBM), Universidade Federal do Rio Grande do Sul (UFRGS). Porto Alegre, RS, Brazil.

3 Serviço de Ginecologia e Obstetrícia, Hospital de Clínicas de Porto Alegre. Porto Alegre, RS, Brazil.

4 Programa de Pós-graduação em Ciências Médicas, Universidade Federal do Rio Grande do Sul (UFRGS). Porto Alegre, RS, Brazil.

Corresponding author: Sandra Leistner-Segal E-mail: ssegal@hcpa.ufrgs.br Serviço de Genética Médica Hospital de Clínicas de Porto Alegre Rua Ramiro Barcelos, 2350. 90035-903, Porto Alegre, RS, Brazil. 
Laboratory prenatal assays, including fetal sex determination, measurement of enzyme activity, and mutation analysis, depend on cultured cells harvested from amniotic fluid, obtained at midtrimester amniocentesis.

We proposed here a new protocol for mutation analysis and prenatal diagnosis of MPS II using free amniotic fluid cells present in the supernatant that did not attach to the bottom of the tissue culture flask after the first medium change.

\section{METHODS}

The Molecular Genetics Laboratory of the Medical Genetics Service of Hospital de Clínicas de Porto Alegre, Brazil, is a reference center for MPS diagnosis and receives samples from all over Brazill. The present study included four MPS II pregnant carriers who were referred for prenatal analysis around 15-16 weeks of gestational age. They all had a previous child with MPS II disease who was diagnosed by the presence of dermatan and heparan sulfate and high concentration of glycosaminoglycans in urine, in addition to low activity of IDS in leukocytes (excluding multiple sulfatase deficiency by another sulfatase measurement) and molecular analysis that identified a hemizygous individual for a specific mutation in the IDS gene after sequencing. The dimethylmethylene blue (DMB) method ${ }^{5}$ was used for glycosaminoglycans quantification, and IDS was measured using a fluorogenic method'.

Only pregnant women who were known to carry a male fetus, as seen by echography examination or fetal sex determination by DNA analysis, were referred for MPSII diagnosis.

An informed consent was obtained by the physician before diagnostic testing. Amniotic fluid was collected at mid-trimester amniocentesis, and the cells were grown for 12 days. Measurement of enzyme activity and cytogenetic analysis were performed for the four pregnant women at high risk for MPS II. Meanwhile, genomic DNA was extracted from the "floating cells" after 5 days of cell culture with the Invisorb ${ }^{\circledR}$ Spin Micro DNA kit (Invitek) and was used as a template for PCR synthesis of IDS-specific amplicons using previously described primers? ${ }^{7}$.

The exons to be amplified were chosen according to previous mutation analysis in the family. Sequencing of IDS genomic amplicons was subsequently performed using ABI Prism 3500 DNA sequencer (Applied Biosystems) according to the protocol provided by the manufacturer.

\section{RESULTS}

Enzyme activity assays showed normal rates (reference values: 50 to $100 \mathrm{nmol} / \mathrm{h} / \mathrm{mg}$ prot) of IDS activity in amniotic fluid cells for cases 1 and 3 and undetectable activity for case 2 (table 1). IDS gene sequencing showed normal male fetus in cases 1 , 3 and 4 and hemizygous for the family mutation in case 2 , confirming the biochemical findings (table 1 ).

Biochemical analysis could not be performed in one case (case 4), because the amount of material derived from the cell culture was not sufficient to achieve a final result. However, we were able to exclude the possibility that the fetus was a carrier of Hunter syndrome by mutation analysis.

\section{DISCUSSION}

During the cell culture procedures, we observed a considerable number of floating cells after the first medium change. These cells are usually discarded; nevertheless, they can be a good source of a considerable amount of DNA for further molecular analysis. Thus, we proposed and developed a protocol for DNA extraction from these cells in order to guarantee a prenatal laboratory result regardless of whether cell culture was successful or not, and also to abbreviate the molecular results in cases of known mutation within the family.

Determination of IDS gene mutation in fetal amniotic fluid cells together with IDS enzyme activity testing is a rapid, sensitive and accurate method for prenatal diagnosis of MPS II in high-risk pregnancies.

Prenatal analysis can be very important for early treatment of severe and progressive diseases by enzyme replacement therapy, bringing new perspectives for patients and families.

Table 1: Molecular, biochemical and cytogenetic results.

\begin{tabular}{lllll}
\hline & \multicolumn{1}{c}{ Case 1 } & \multicolumn{1}{c}{ Case 2 } & \multicolumn{1}{c}{ Case 3 } & \multicolumn{1}{c}{ Case 4 } \\
\hline Mother's age & 27 years old & 36 years old & 36 years old & 33 years old \\
Mutation* & Absence (p.D45G) & Presence (p.P231L) & Absence (p.R468W) & Absence (p.H335R) \\
Karyotype & $46, \mathrm{XY}$ & $46, \mathrm{XY}$ & $46, \mathrm{XY}$ & $46, \mathrm{XY}$ \\
Enzyme activity & Normal & Undetectable & Normal & Not performed \\
& $80 \mathrm{nmol} / \mathrm{h} / \mathrm{mg}$ prot & & $36 \mathrm{nmol} / \mathrm{h} / \mathrm{mg}$ prot & \\
\hline
\end{tabular}

\footnotetext{
${ }^{*}$ Mutation found previously in the index case. ${ }^{* *}$ Culture failure.
} 
The identification of the gene defect is not required for MPS II diagnosis but can be helpful for phenotype prediction and for the identification of carriers. Carriers frequently exhibit an enzyme activity in between the ranges of affected patients and normal controls, but some overlap is usually observed; therefore, enzyme activity levels cannot be used alone to predict carrier status ${ }^{3}$.

MPS II shows wide allelic and phenotypic heterogeneity ${ }^{4}$. Patients are usually classified as having the severe or attenuated forms, depending mainly on the degree of mental retardation ${ }^{2,3}$. In general, it seems that patients with the more severe forms are diagnosed earlier, have mental retardation that is evident by the age of 4-6 years, and are dead by the age of 10-15 years, while patients with the attenuated forms have normal intelligence ${ }^{2,8,9}$. However, as there is no standardized scoring index of severity for MPS II, this classification is not always reliable, especially in the case of patients diagnosed during childhood ${ }^{9}$.

The cases presented here illustrate the importance of a comprehensive prenatal diagnostic protocol to provide more robust results and safer genetic counseling.
A molecular approach was incorporated into our prenatal routine in order to obtain a rapid diagnosis and allow for sex determination and mutation detection within a few days after biological samples were collected, decreasing the time for final report.

This protocol using free amniotic fluid cells can be used for many other diseases that can benefit from molecular diagnosis for definition of the fetus status even in the event of a culture failure. Taking into account the advent of next generation sequencing for molecular diagnosis on minimum amounts of biological material, this approach would be highly recommended.

\section{Acknowledgements}

This study was supported by FIPE-HCPA funds. ACBF receives a governmental post-doctoral scholarship from CAPES. SLS and RG are receipients of CNPq research grants.

\section{Conflicts of interest}

The authors inform that there are no conflicts of interest.

\section{REFERENCES}

1. de Camargo Pinto LL, Maluf SW, Leistner-Segal S, Zimmer da Silva C, Brusius-Facchin A, Burin MG, et al. Are MPS II heterozygotes actually asymptomatic? A study based on clinical and biochemical data, X-inactivation analysis and imaging evaluations. Am J Med Genet A. 2011;155A(1):50-7. http:// dx.doi.org/10.1002/ajmg.a.33770. PMid:21204210

2. Neufeld EF, Muenzer J. The Mucopolysaccharidoses. In: Scriver CR, Beaudet AL, Sly WS, Valle D, editors. The metabolic and molecular basis of inherited disease. 7th ed. New York: McGraw-Hill; 2001. p. 1191-211.

3. Schwartz IV, Ribeiro MG, Mota JG, Toralles MB, Correia P, Horovitz $D$, et al. A clinical study of 77 patients with mucopolysaccharidosis type II. Acta Paediatr Suppl. 2007;96(455):6370. http://dx.doi.org/10.1111/j.1651- 2227.2007.00212.x. PMid:17391446

4. Brusius-Facchin AC, Schwartz IV, Zimmer C, Ribeiro MG, Acosta AX, Horovitz D, et al. Mucopolysaccharidosis type II: identification of 30 novel mutations among Latin American patients. Mol Genet Metab. 2014;111(2):1338. http://dx.doi.org/10.1016/j. ymgme.2013.08.011. PMid:24125893

5. de Jong JG, Wevers RA, Liebrandvan Sambeek R. Measuring urinary glycosaminoglycans in the presence of protein: an improved screening procedure for mucopolysaccharidoses based on dimethylmethylene blue. Clin Chem. 1992;38(6):803-7. PMid:1597005.

6. Voznyi YV, Keulemans JL, van Diggelen OP. A fluorimetric enzyme assay for the diagnosis of MPS II (Hunter disease). $J$ Inherit Metab Dis. 2001;24(6):675-80. http://dx.doi. org/10.1023/A:1012763026526.
PMid:11768586

7. Goldenfum SL, Young E, Michelakakis $\mathrm{H}$, Tsagarakis S, Winchester B. Mutation analysis in 20 patients with Hunter disease. Hum Mutat. 1996;7(1):76-8. http:// dx.doi.org/10.1002/(SICI)10981004(1996)7:1<76::AIDHUMU14>3.0.CO;2-P. PMid:8664909

8. Young ID, Harper PS, Newcombe RG, Archer IM. A clinical and genetic study of Hunter's syndrome. 2. Differences between the mild and severe forms. $J$ Med Genet. 1982;19(6):408-11. http:// dx.doi.org/10.1136/jmg.19.6.408. PMid:6818348

9. Froissart R, Silva IM, Guffon N, Bozon D, Maire I. Mucopolysaccharidosis type II-genotype/phenotype aspects. Acta Paediatr Suppl. 2002;91(439):82-7. http://dx.doi. org/10.1111/j.1651-2227.2002. tb03116.x. PMid:12572848 